\title{
Predictors of long-term clinical response in patients with non-radiographic axial spondyloarthritis receiving certolizumab pegol
}

Walter P. Maksymowych ${ }^{1 *} \mathbb{C}$, Thomas Kumke², Simone E. Auteri ${ }^{3}$ (D) Bengt Hoepken², Lars Bauer ${ }^{2}$ and Martin Rudwaleit ${ }^{4}$

\begin{abstract}
Background: Identification of predictive clinical factors of long-term treatment response may contribute to improved management of non-radiographic axSpA (nr-axSpA) patients. This analysis aims to identify whether any baseline characteristics or Week 12 clinical outcomes in nr-axSpA patients with elevated C-reactive protein (CRP) and/ or sacroiliitis on magnetic resonance imaging (MRI) enrolled in the C-axSpAnd study are predictive of achieving clinical response after 1 year of certolizumab pegol (CZP).
\end{abstract}

Methods: C-axSpAnd (NCT02552212) was a phase 3, multicentre study, including a 52-Week double-blind, placebocontrolled period. Enrolled patients were randomised to CZP $200 \mathrm{mg}$ Q2W or placebo. Predictors of Week 12 (CZP group only) and Week 52 clinical response were identified using a multivariate stepwise logistic regression analysis. Response variables included Ankylosing Spondylitis Disease Activity Score major improvement (ASDAS-MI), Assessment of SpondyloArthritis International Society 40\% response (ASAS40), Bath Ankylosing Spondylitis Disease Activity Index 50\% response (BASDAI50) and ASDAS inactive disease (ASDAS-ID). Predictive factors assessed included demographic and baseline characteristics and clinical outcomes at Week 12. A $p$-value $<0.05$ was required for forward selection into the model and $p \geq 0.1$ for backward elimination. Missing data or values collected after switching to openlabel treatment were accounted for using non-responder imputation. Sensitivity analyses accounted for patients with changes in non-biologic background medication.

Results: Of 317 enrolled patients, 159 and 158 were randomised to CZP and placebo, respectively. Younger age and male sex were identified as predictors of Week 12 response across all assessed efficacy outcomes in CZP-treated patients. Consistent predictors of Week 52 response, measured by ASDAS-MI, ASAS40 and BASDAI50, included human leukocyte antigen (HLA)-B27 positivity and sacroiliitis on MRI at baseline. MRI positivity was also predictive of achieving ASDAS-ID at Week 52. Sensitivity analyses were generally consistent with the primary analysis. In placebo-treated patients, no meaningful predictors of Week 52 response were identified.

Conclusions: In this 52-Week, placebo-controlled study in nr-axSpA patients with elevated CRP and/or active sacroiliitis on MRI at baseline, MRI sacroiliitis and HLA-B27 positivity, but not elevated CRP or responses at Week 12, were predictive of long-term clinical response to CZP. Findings may support rheumatologists to identify patients suitable for TNFi treatment.

Trial registration: ClinicalTrials.gov, NCT02552212. Registered on 15 September 2015

\footnotetext{
*Correspondence: walter.maksymowych@ualberta.ca

1 University of Alberta, Edmonton, Canada

Full list of author information is available at the end of the article
} original author(s) and the source, provide a link to the Creative Commons licence, and indicate if changes were made. The images or other third party material in this article are included in the article's Creative Commons licence, unless indicated otherwise in a credit line to the material. If material is not included in the article's Creative Commons licence and your intended use is not permitted by statutory regulation or exceeds the permitted use, you will need to obtain permission directly from the copyright holder. To view a copy of this licence, visit http://creativecommons.org/licenses/by/4.0/. The Creative Commons Public Domain Dedication waiver (http://creativeco mmons.org/publicdomain/zero/1.0/) applies to the data made available in this article, unless otherwise stated in a credit line to the data. 
Keywords: TNF inhibitor, Axial spondyloarthritis, Predictors, Certolizumab pegol

\section{Background}

Diagnosis can often be a challenge in non-radiographic axial spondyloarthritis (nr-axSpA); the presence of sacroiliitis on magnetic resonance imaging (MRI), human leukocyte antigen (HLA)-B27 and acute phase reactants such as serum $\mathrm{C}$-reactive protein (CRP) remain the most reliable diagnostic tests but with limited specificity and/ or sensitivity [1-3]. Patients with nr-axSpA are less likely to be treated with a biologic than patients with radiographic (r)-axSpA (also known as ankylosing spondylitis), despite a similar burden of disease on quality of life [4]. This may be due to the barriers associated with nraxSpA diagnosis. Up to $25 \%$ of patients with nr-axSpA in the USA may face diagnostic delays of $\geq 11$ years, during which time radiographic progression may occur $[5,6]$.

Personalised therapy using molecular and genetic profiling represents the optimal goal in the management of axSpA. The ASAS-EULAR task force highlights the value of predicting treatment response in axSpA and proposes that patients with high disease activity and objective signs of inflammation, defined as sacroiliac joint (SIJ) inflammation on MRI (MRI+) or elevated CRP level (CRP+), are suitable candidates for TNFi therapy $[7,8]$. This is, in part, based on findings from randomised controlled trials in $\mathrm{nr}-\mathrm{axSpA}$, which suggested a better response to tumour necrosis factor inhibitor (TNFi) treatment in subgroups of patients with elevated CRP and/or MRI at baseline. However, it should be noted that these recommendations rely on non-significant outcomes, with primary endpoints reported for patients randomised to placebo or TNFi for a maximum of 12 or 16 Weeks, respectively [9-11].

Younger age, male sex, elevated CRP, HLA-B27 positivity and lower Bath Ankylosing Spondylitis Functional Index (BASFI) scores at baseline have been identified as predictors of good clinical response to TNFi across clinical trials and observational historical cohort studies in r-axSpA after 3-6 months of treatment [12-18]. However, there are fewer predictive analyses in $\mathrm{nr}$-axSpA, with available data limited to short-term treatment responses only $[9-11,19]$. The identification of predictive clinical factors of long-term response in $\mathrm{nr}$-axSpA may help to differentiate appropriate patients suitable for TNFi treatment, while providing confidence in the treatment choice from both a physician and patient perspective, particularly in the early disease phase.

C-axSpAnd (NCT02552212) was a 52-Week placebocontrolled study to investigate the efficacy of a TNFi in a nr-axSpA population and resulted in the FDA approval of certolizumab pegol (CZP) as the first and currently only TNFi indicated for the treatment of nr-axSpA in the USA $[20,21]$. All enrolled patients had elevated CRP and/or MRI and high disease activity despite prior non-steroidal anti-inflammatory drug (NSAID) use. C-axSpAnd was therefore designed to investigate CZP in patients with nr-axSpA, comparing the clinical benefit of a TNFi treatment with non-biologic background medication (NBBM) [21]. This post hoc analysis from C-axSpAnd aims to identify whether any baseline characteristics or Week 12 clinical outcomes in patients with nr-axSpA are predictive of achieving a clinical response after 1 year of CZP or placebo treatment.

\section{Patients and methods Study design}

C-axSpAnd (AS0006, ClinicalTrials.gov number NCT02552212) was a 3-year, phase 3 study, including a 52-Week, randomised, placebo-controlled, double-blind period, followed by a 2-year open-label follow-up extension [21]. The aim of the study was to investigate the clinical efficacy and safety of CZP in patients with active nr-axSpA and elevated CRP and/or MRI compared with placebo and on top of NBBM, such as corticosteroids. The primary endpoint of the study was the achievement of Ankylosing Spondylitis Disease Activity Score major improvement (ASDAS-MI) at Week 52, defined as a reduction of $\geq 2.0$ points in ASDAS relative to baseline, or when the lowest possible score was achieved (0.6) [21, 22]. This post hoc analysis aims to identify predictive factors of long-term clinical response to CZP or placebo in these patients.

Eligible patients were $\geq 18$ years of age, had documented adult-onset nr-axSpA, fulfilling Assessment of SpondyloArthritis International Society (ASAS) classification criteria [23], with active disease, symptom duration of $\geq 12$ months and previous inadequate response or contraindication to $\geq 2$ NSAIDs. Patients were also required to have elevated CRP and/or active sacroiliitis on MRI (based on the ASAS/Outcome Measures in Rheumatology [OMERACT] definition of a positive MRI [MRI+]) [24] at screening and/or elevated CRP levels $(C R P+)$ at baseline, which were above the upper limit of normal (ULN, $\geq 10.0 \mathrm{mg} / \mathrm{L}$ ). Patients with radiographic sacroiliitis meeting the modified New York (mNY) classification criteria [25], as well as exposure to $>1$ TNFi prior to baseline or primary failure to any TNFi therapy, were excluded. All MRI and SIJ X-rays were centrally assessed by two readers and an adjudicator (if 
necessary). Assessment of CRP was performed in a central laboratory.

Eligible patients were randomised 1:1 to either CZP $200 \mathrm{mg}$ Q2W (400 mg loading dose at Weeks 0, 2 and 4) or placebo; all patients received randomised treatment (CZP or placebo) on top of any NBBM. NBBM could be adjusted at the discretion of the investigator, although preferably not before Week 12, or within 4 Weeks prior to Weeks 24 and 52. Permitted concomitant medications are listed in the Supplementary Material. Switching to open-label CZP or alternative treatment was permitted at any point during the study. However, patients were encouraged to remain on randomised treatment until at least Week 12.

Full C-axSpAnd study design, as well as primary and secondary results, are reported elsewhere [21].

\section{Predictor analysis}

Univariate analysis and subsequent multivariate logistic regression with stepwise variable selection was used to identify predictors of Week 12 and Week 52 response in the CZP treatment groups for the following efficacy outcomes: ASDAS-MI, ASAS 40\% response (ASAS40), Bath Ankylosing Spondylitis Disease Activity Index $50 \%$ response (BASDAI50) and ASDAS inactive disease (ASDAS-ID [ASDAS <1.3]). All efficacy outcomes at Week 52 were also assessed for patients randomised to placebo.

Demographic and baseline characteristics, as well as Week 12 clinical outcomes (for the Week 52 analysis only), were included in the predictive model as either continuous or categorical variables. CRP level, MRI and HLA-B27 status were assessed as variables of special interest (see Supplementary Material for a full list of variables assessed). Smoking status was not included in the model as a potential predictor of response due to the small number of smokers enrolled in the trial (CZP: $n$ =27; placebo: $n=18$ ). Variables were initially assessed in a univariate analysis, with significant results subsequently included in the multivariate selection model. A $p$-value $<0.05$ was required for forward selection into the model and $p \geq 0.1$ for backward elimination from the model. The final logistic model included collinearity diagnostics. All patients who were randomised into the study (Randomised Set) were included in the analysis. Non-responder imputation was used to account for missing data or values collected after switching to openlabel treatment.

A sensitivity analysis was conducted to identify predictors of response for all four response variables, excluding patients who had changes in NBBM during the 52-Week placebo-controlled phase. An additional analysis was also performed to investigate interaction effects in the Week
12 and Week 52 models. The following interaction effect variables were considered: MRI*HLA-B27, sex*MRI, age*MRI, CRP*MRI, sex*CRP and age*CRP.

Predictive factors are reported as odds ratios (OR) with 95\% confidence intervals (CI). Statistical analyses were performed using SAS version 9.4 or above.

\section{Results \\ Patients}

A total of 317 patients with nr-axSpA and elevated CRP and/or active sacroiliitis on MRI (MRI positive or MRI negative) were enrolled in $\mathrm{C}$-axSpAnd and were randomised to either CZP $200 \mathrm{mg}$ Q2W $(n=159)$ plus NBBM or placebo $(n=158)$ plus NBBM. Of the 282 patients who completed the Week 52 visit, 180 remained on randomised double-blind treatment (CZP: $n=125$; placebo: $n=55$ ). Baseline demographics and characteristics were representative of a nr-axSpA patient population and were well-balanced between treatment groups (Table 1).

\section{Predictors of Week 12 response}

The percentages of patients achieving an ASDAS-MI, ASAS40, BASDAI50 or ASDAS-ID response at Week 12 are reported in Table 2. Younger age and male sex were associated with all analysed response variables (ASDAS-MI, ASAS40, BASDAI50 and ASDAS-ID) at Week 12 for CZP-treated patients (Fig. 1). Achievement of ASDAS-MI at Week 12 was also associated with elevated CRP levels and higher Patient Global Assessment of Disease Activity (PtGADA) at baseline (Fig. 1A). Univariate analyses are reported in Supplementary Figure S1. Variance inflation factors ranged between 1.02 and 1.06 and tolerance ranged between 0.94 and 0.98 , indicating that potential bias due to multicollinearity is negligible.

\section{Predictors of Week 52 response}

The percentages of patients achieving an ASDAS-MI, ASAS40, BASDAI50 or ASDAS-ID response at Week 52 are reported in Table 2. Predictive factors identified for Week 52 ASDAS-MI in CZP-treated patients included being positive for both presence of sacroiliitis on MRI and HLA-B27, having a higher BASDAI at baseline and having a greater Week 12 improvement in ASDAS (Fig. 2A). For ASAS40 response, MRI+/HLA-B27+ was also identified as a predictor of Week 52 response, along with a lower BASMI and greater Week 12 improvements in PtGADA and ankylosing spondylitis quality of life (ASQoL, Fig. 2B). Positive MRI/HLA-B27 status, greater Week 12 improvements in BASDAI and ASQoL, and a Maastricht Ankylosing Spondylitis Enthesitis Score (MASES) of 0 at baseline were associated with Week 52 BASDAI50 (Fig. 2C). Achievement of 
Table 1 Baseline demographics and patient characteristics

\begin{tabular}{|c|c|c|}
\hline & $\begin{array}{l}\text { Placebo } \\
+ \text { NBBM } \\
(n=158)\end{array}$ & $\begin{array}{l}\text { CZP } 200 \mathrm{mg} \text { Q2W } \\
+ \text { NBBM } \\
(n=159)\end{array}$ \\
\hline Age (years), mean (SD) & $37.4(10.8)$ & $37.3(10.5)$ \\
\hline Female, $n(\%)$ & $82(52)$ & $81(51)$ \\
\hline HLA-B27 positive, $n(\%)$ & $132(84)$ & $128(81)$ \\
\hline Caucasian, $n(\%)$ & $148(94)$ & $152(96)$ \\
\hline Symptom duration (years), mean (SD) & $8.0(7.5)$ & $7.8(7.7)$ \\
\hline Time since first diagnosis (years), mean (SD) & $4.0(5.4)$ & $3.6(4.8)$ \\
\hline ASDAS, mean (SD) & $3.8(0.9)$ & $3.8(0.8)$ \\
\hline BASDAI score, mean (SD) & $6.8(1.3)$ & $6.9(1.4)$ \\
\hline BASFI score, mean (SD) & $5.4(2.2)$ & $5.4(2.1)$ \\
\hline BASMI score, mean (SD) & $2.8(1.4)$ & $3.0(1.3)$ \\
\hline CRP (mg/L), mean (SD) & $15.8(17.7)$ & $15.8(17.8)$ \\
\hline Elevated CRP at baseline (>ULN), $n(\%)$ & $83(53)$ & $89(56)$ \\
\hline \multicolumn{3}{|l|}{ MRI/CRP classification, $n(\%)$} \\
\hline $\mathrm{MRI}+/ \mathrm{CRP}+$ & $42(27)$ & $45(28)$ \\
\hline $\mathrm{MRI}+/ \mathrm{CRP}-$ & $76(48)$ & $74(47)$ \\
\hline $\mathrm{MRI}-/ \mathrm{CRP}+$ & $39(25)$ & $38(24)$ \\
\hline Sacroiliac joint MRI SPARCC score, mean (SD) & $8.5(12.3)$ & $7.8(10.8)$ \\
\hline Sacroiliac joint MRI SPARCC score $\geq 2, n(\%)$ & $129(82)$ & $136(86)$ \\
\hline Nocturnal spinal pain score, mean (SD) & $6.6(2.1)$ & $6.6(2.3)$ \\
\hline \multicolumn{3}{|l|}{ Past treatment, ${ }^{\mathrm{a}} n(\%)$} \\
\hline NSAIDs & $144(91)$ & $143(90)$ \\
\hline DMARDs $^{\mathrm{b}}$ & $46(29)$ & $44(28)$ \\
\hline Tumour necrosis factor inhibitors & $11(7)$ & $7(4)$ \\
\hline \multicolumn{3}{|l|}{ Concomitant treatment, $n(\%)$} \\
\hline NSAIDs & $138(87)$ & $138(87)$ \\
\hline DMARDs & $48(30)$ & $55(35)$ \\
\hline Systemic corticosteroids & $26(17)$ & $27(17)$ \\
\hline
\end{tabular}

Randomised set $(N=317)$. All patient-reported outcomes were assessed using a numerical rating scale $(0-10)$, with higher numbers indicating poorer outcomes. ${ }^{a}$ Medications with an end date before the baseline visit; ${ }^{b}$ includes biologic DMARDs and conventional synthetic DMARDs. ASDAS Ankylosing Spondylitis Disease Activity Score, BASDAI Bath Ankylosing Spondylitis Disease Activity Index, BASFI Bath Ankylosing Spondylitis Functional Index, BASMI Bath Ankylosing Spondylitis Metrology Index, CRP C-reactive protein, CZP certolizumab pegol, DMARD disease-modifying antirheumatic drug, $H L A-B 27$ human leukocyte antigen B27, MRI magnetic resonance imaging, NBBM non-biologic background medication, NSAID non-steroidal anti-inflammatory drug, Q2W every 2 Weeks, SD standard deviation, SPARCC Spondyloarthritis Research Consortium of Canada, ULN upper limit of normal (9.99 mg/L)

Table 2 Percentage of patients achieving a response at Week 12 and Week 52 (NRI)

\begin{tabular}{|c|c|c|c|c|}
\hline \multirow[t]{2}{*}{$n(\%)$} & \multicolumn{2}{|l|}{ Week 12} & \multicolumn{2}{|l|}{ Week 52} \\
\hline & $\begin{array}{l}\text { Placebo } \\
+ \text { NBBM } \\
(n=158)\end{array}$ & $\begin{array}{l}\text { CZP } 200 \mathrm{mg} Q 2 W \\
+ \text { NBBM } \\
(n=159)\end{array}$ & $\begin{array}{l}\text { Placebo } \\
+ \text { NBBM } \\
(n=158)\end{array}$ & $\begin{array}{l}\text { CZP } 200 m g \text { Q2W } \\
+ \text { NBBM } \\
(n=159)\end{array}$ \\
\hline ASDAS-MI & $10(6.3)$ & $56(35.2)$ & $11(7.0)$ & $75(47.2)$ \\
\hline ASAS40 & $18(11.4)$ & $76(47.8)$ & 25 (15.8) & 90 (56.6) \\
\hline BASDAI50 & 23 (14.6) & $68(42.8)$ & $19(12.0)$ & $88(55.3)$ \\
\hline ASDAS-ID & $2(1.3)$ & $26(16.4)$ & $6(3.8)$ & $44(27.7)$ \\
\hline
\end{tabular}

ASAS40 Assessment of SpondyloArthritis International Society 40\%, ASDAS Ankylosing Spondylitis Disease Activity Score, ASDAS-ID ASDAS inactive disease (ASDAS $<1.3)$, ASDAS-MI ASDAS major improvement (reduction in ASDAS $\geq 2.0$ ), BASDAI50 Bath Ankylosing Spondylitis Disease Activity Index 50\%, NRI non-responder imputation, Q2W every 2 Weeks 
ASDAS-ID at Week 52 was associated with MRI positivity, prior exposure to $\leq 2$ NSAIDs, lower BASFI at baseline and greater BASDAI Week 12 improvement. Reaching ASDASID at Week 12 also increased the likelihood of having ASDAS-ID at Week 52 (Fig. 2D). Univariate analyses for Week 52 responses in CZP-treated patients are reported in Supplementary Figure $\mathrm{S} 2$.

No meaningful predictors of Week 52 response were identified in placebo-randomised patients; there were no outputs for the multivariate analysis as data were nonsignificant (data not shown). A summary of Week 12 and Week 52 predictive factors of response in CZP-treated patients is shown in Table 3.

Variance inflation factors ranged between 1.00 and 1.65 and tolerance ranged from 1.00 to 0.60 , indicating a slight presence of multicollinearity.

\section{Sensitivity analysis}

A sensitivity analysis accounting for changes in background medication identified the same predictors for ASDAS-MI and ASAS40, with the exception of change from baseline in PtGADA as a predictor of ASAS40. Sensitivity analysis also identified achievement of Week 12 ASAS40 as a predictor of Week 52 ASAS40 (Supplementary Figure S3). Sensitivity analysis for Week 52 BASDAI50 was generally consistent with the primary analysis, excluding low MASES $($ MASES $=0$ ) at baseline. ASDAS-ID at Week 12 and lower BASFI at baseline were identified as predictors of Week 52 ASDAS-ID in the sensitivity analysis, in addition to positive MRI/HLA-B27 status and BASDAI50 at Week 12. MRI positivity (as a dichotomous measure) and prior NSAID exposure were not significantly associated with Week 52 ASDAS-ID in CZP-treated patients who did not experience changes in background medication.

\section{Interaction effects analysis}

The results from the interaction effects analysis were mostly non-significant. Significant interaction effects were identified between MRI and HLA-B27 status for Week 52 ASDAS-MI, ASAS40, BASDAI50 and ASDASID responses (Table 4). A significant association between sex and MRI was also identified for Week 52 ASDAS-MI and ASDAS-ID responses (Table 4).

\section{Discussion}

In this report from a double-blinded, 52-Week placebocontrolled study, we investigated predictors of clinical response in a $\mathrm{nr}$-axSpA population with objective signs of inflammation by elevated CRP and/or positive MRI. Specifically, this analysis aimed to establish whether any demographic and baseline characteristics or clinical outcomes at Week 12 are predictive of achieving long-term clinical response to CZP in patients with nr-axSpA and elevated CRP and/or active sacroiliitis on MRI, thereby supporting rheumatologists to identify patients suitable for TNFi treatment.

In the Week 12 analysis, younger age and male sex were identified as consistent predictors of response across all clinical outcomes, including ASDAS-MI, ASAS40, BASDAI50 and ASDAS-ID. This is similar to another analysis, which also identified younger age and male sex as predictors of ASDAS-ID response and ASAS partial remission in patients with nr-axSpA who were treated with adalimumab over a 28 -Week open-label lead-in period [26]. The finding that younger patients and males were associated with predictors of Week 12 but not Week 52 response in this analysis may indicate a delayed or weaker treatment response in females and older individuals; however, this remains unclear. Several studies have identified a significant difference in TNFi treatment response between male and female patients with $\mathrm{r}$-axSpA, which may be attributed to possible differences in immunological, hormonal and genetic responses [27]. Additional data in nr-axSpA patients have also been reported supporting this observation. These findings may highlight the challenges of making an accurate diagnosis of nr-axSpA in females and the potential for disease misclassification in these patients [28].

Consistent predictors of Week 52 response in CZPtreated patients, as measured by ASDAS-MI, ASAS40 and BASDAI50, included HLA-B27 positivity and presence of sacroiliitis on MRI at baseline. MRI positivity was also predictive of achieving ASDAS-ID at Week 52. It is notable that these predictive factors were all objective features of disease and generally demonstrated stronger

\footnotetext{
(See figure on next page.)

Fig. 1 Predictive factors of Week 12 response in CZP-treated patients.

Randomised set (NRI). Patients received CZP 200 mg Q2W (400 mg loading dose at Weeks 0, 2 and 4) plus non-biologic background medication. ancluded in the predictive model as continuous variables; for these factors, an odds ratio $>1$ indicates a higher probability of larger values being predictive of a response. ASAS40 Assessment of SpondyloArthritis International Society 40\%, ASDAS Ankylosing Spondylitis Disease Activity Score, ASDAS-ID ASDAS inactive disease (ASDAS <1.3), ASDAS-MI ASDAS major improvement (reduction in ASDAS $\geq 2.0$ ), BASDAI50 Bath Ankylosing Spondylitis Disease Activity Index 50\%, Cl confidence interval, CRP C-reactive protein, CZP certolizumab pegol, NRI non-responder imputation, PtGADA Patient's Global Assessment of Disease Activity, Q2W every 2 Weeks, ULN upper limit of normal (9.99 mg/L), vs versus
} 


\section{A) Predictive factors for ASDAS-MI}

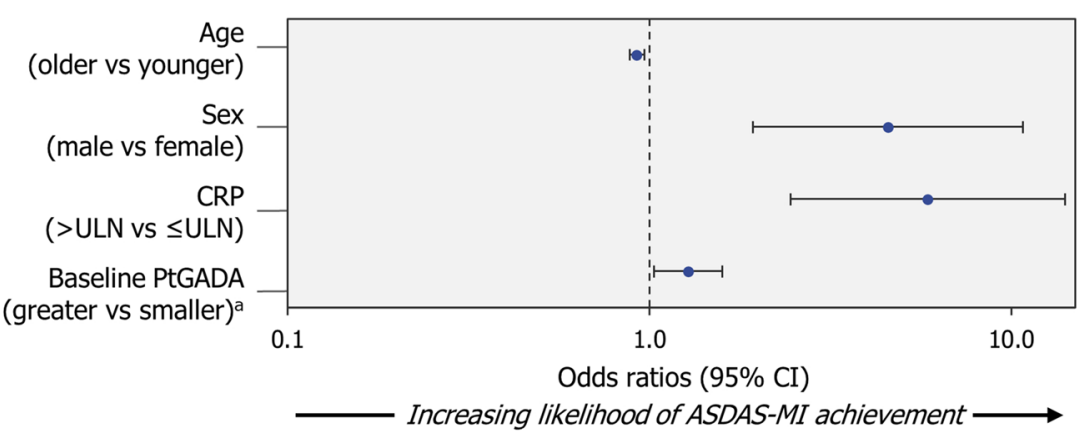

Odds ratio $(95 \% \mathrm{CI})$

$0.92(0.88-0.97)$

$4.55(1.93-10.76)$

$5.87(2.45-14.07)$

$1.28(1.04-1.59)$

B) Predictive factors for ASAS40

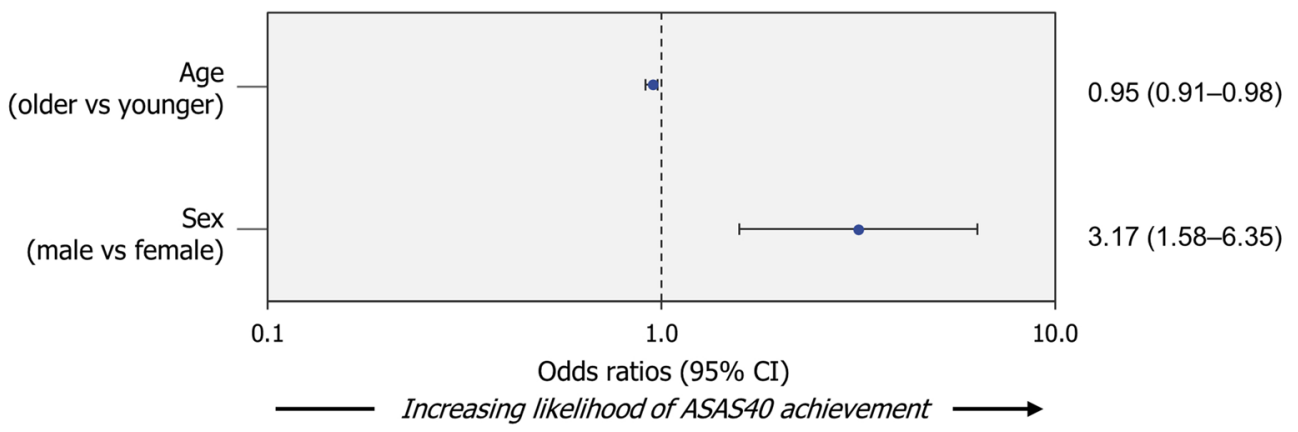

\section{C) Predictive factors for BASDAI50}

Odds ratio (95\% CI)

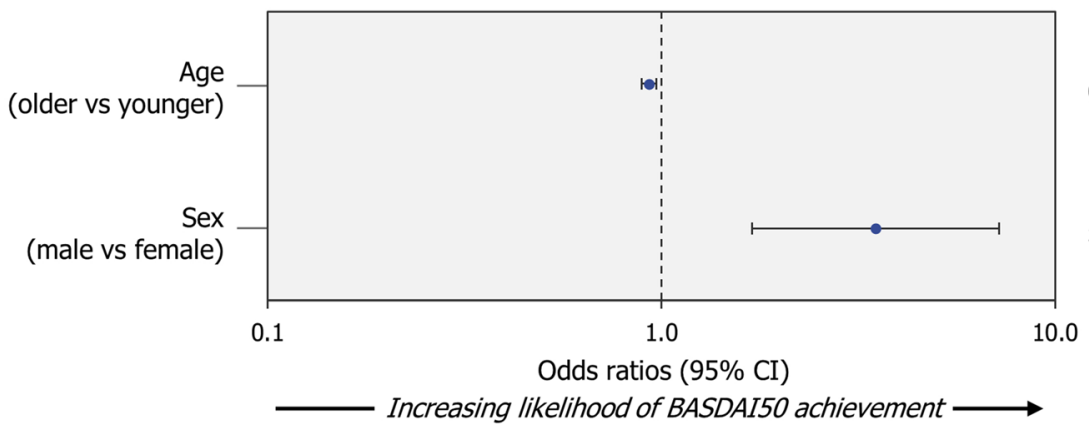

$0.93(0.89-0.97)$

$3.50(1.70-7.20)$

Increasing likelihood of BASDAI50 achievement

Odds ratio $(95 \% \mathrm{CI})$

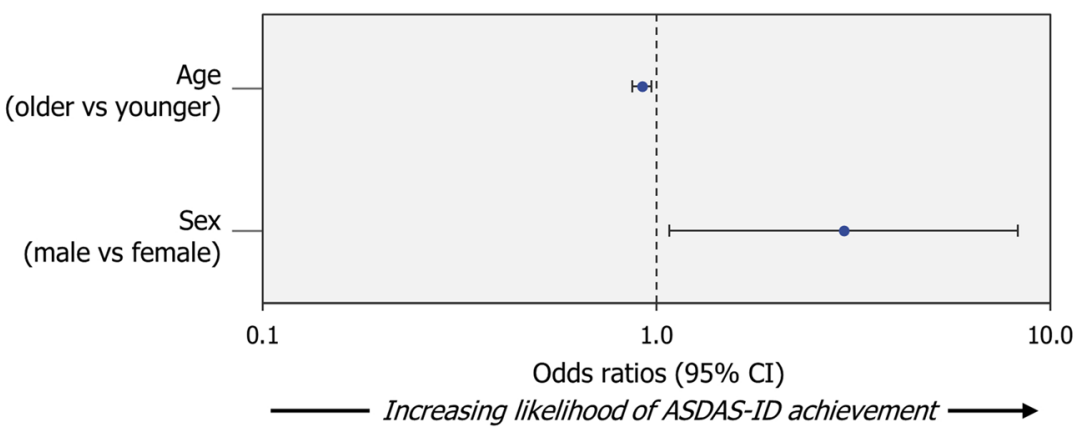

$0.92(0.87-0.97)$

$2.99(1.08-8.28)$

Fig. 1 (See legend on previous page.) 
associations than the predictors of response identified for Week 12. Moreover, MRI scans were centrally read by trained readers, increasing confidence that true MRI sacroiliitis was identified. The use of SIJ MRI, in addition to clinical examination and assessment of CRP levels, is encouraged to aid the diagnosis of axSpA and in some countries is a mandatory requirement for the initiation of TNFi $[7,8]$. Widespread inflammation on MRI, particularly in the spine, has been associated with a good clinical response to TNFi therapy in $\mathrm{r}$-axSpA [12]. Although previous studies have evaluated the prognostic value of MRI in nr-axSpA [26], most findings are data extracted from correlation analyses $[9,29]$.

Overall, the findings of this analysis are comparable with analyses in $\mathrm{r}$-axSpA, which have identified predictors of clinical response following up to 6 months of TNFi treatment [12-19]. However, in contrast to previous studies, elevated CRP (included as a categorical variable, $\leq />$ upper limit of normal) was not identified as a predictive factor for any evaluated efficacy outcome, except Week 12 ASDAS-MI. Compared with other predictive analyses, C-axSpAnd enrolled patients with elevated CRP and/or active sacroiliitis on MRI, which reflects current ASAS-EULAR recommendations for the initiation of TNFi therapy in axSpA $[7,8]$. Patients included in this analysis therefore generally had greater baseline CRP levels than previously reported, which may explain why CRP was not identified as a predictor of long-term clinical response. It should also be noted that the demographics of patients with $\mathrm{nr}$-axSpA are different from the r-axSpA populations previously studied, which may influence treatment response; for instance, patients with $\mathrm{nr}$-axSpA are more likely to be female and tend to have shorter symptom duration [30].

An observational study in a cohort of patients with early axSpA has also demonstrated the limited predictive capacity of CRP, with sacroiliitis on MRI identified as the only predictor of TNFi response. However, compared with C-axSpAnd, patients were not selected for elevated MRI and/or CRP; eligible patients were required to have inflammatory back pain, with approximately $30 \%$ presenting with radiographic sacroiliitis meeting $\mathrm{mNY}$ classification criteria at baseline [31].

Compared with previous predictive analyses in axSpA, this analysis exhibits a number of strengths. Firstly, data are reported over a 52-Week treatment period, which is the longest time exposure with a biologic in a controlled setting, allowing the identification of long-term predictors of response. A greater number of potential predictors of response are also evaluated, including responses at Week 12, with variables such as age included in the predictive model as continuous variables, rather than using arbitrary cutoffs. MRI and HLA-B27 status are also included as both combined and individual variables in the model. Although it was not possible in this analysis due to the selection criteria, it would be interesting to evaluate clinical responses in a subgroup of patients who were MRI+/HLA-B27 - as compared to MRI-/HLA-B27-. It should be noted that the patients with axSpA who were MRI-/HLA-B27- were excluded from the study, as dictated by ASAS classification criteria [23]. Stringent measures of axSpA disease activity were also used in this analysis, including ASDAS-ID and ASDAS-MI, which were assessed as clinical endpoints. However, it remains unclear whether some of the identified predictors, such as Week 12 ASQoL improvements, had a true impact on clinical response or were statistically related to the study endpoints.

\section{Conclusions}

To our knowledge, this is the first report from an interventional 52-Week placebo-controlled study in nraxSpA to identify disease-related features, particularly the presence of sacroiliac joint inflammation and HLAB27 positivity, as being predictive of long-term clinical response to CZP treatment. These findings may support rheumatologists to identify patients suitable for TNFi treatment and inform future research within the biologic class.

\footnotetext{
(See figure on next page.)

Fig. 2 Predictive factors of Week 52 response in CZP-treated patients.

Randomised set (NRI). Patients received CZP 200 mg Q2W (400 mg loading dose at Weeks 0, 2 and 4) plus non-biologic background medication. alncluded in the predictive model as continuous variables; for these factors, an odds ratio $>1$ indicates a higher probability of larger values being predictive of a response. For Week 12 change from baseline measures, a lower (negative) value is indicative of improvement, while larger (positive) values indicate worsening. ASAS40 Assessment of SpondyloArthritis International Society 40\%, ASDAS Ankylosing Spondylitis Disease Activity Score, ASDAS-ID ASDAS inactive disease (ASDAS<1.3), ASDAS-MI ASDAS major improvement (reduction in ASDAS $\geq 2.0$ ), ASQoL ankylosing spondylitis quality of life, BASDAI50 Bath Ankylosing Spondylitis Disease Activity Index 50\%, BASFI Bath Ankylosing Spondyloarthritis Functional Index, BASMI Bath Ankylosing Spondylitis Metrology Index, Cl confidence interval, CZP certolizumab pegol, HLA-B27 human leukocyte antigen-B27, MRI+/presence/absence of sacroiliitis on magnetic resonance imaging, MASES Maastricht Ankylosing Spondylitis Enthesitis Score (range 0-13), NRI non-responder imputation, NSAID non-steroidal anti-inflammatory drug, PtGADA Patient Global Assessment of Disease Activity, Q2W every 2 Weeks, vs versus
} 


\section{A) Predictive factors for ASDAS-MI}

Odds ratio $(95 \% \mathrm{CI})$

MRI+/HLA-B27+ $(n=90)$ vs
MRI-/HLA-B27+ $(n=38)$

Baseline BASDAI (greater vs smaller) $^{\mathrm{a}}$

Smaller improvement in ASDAS at Week 12 (vs greater improvement) ${ }^{\mathrm{a}}$

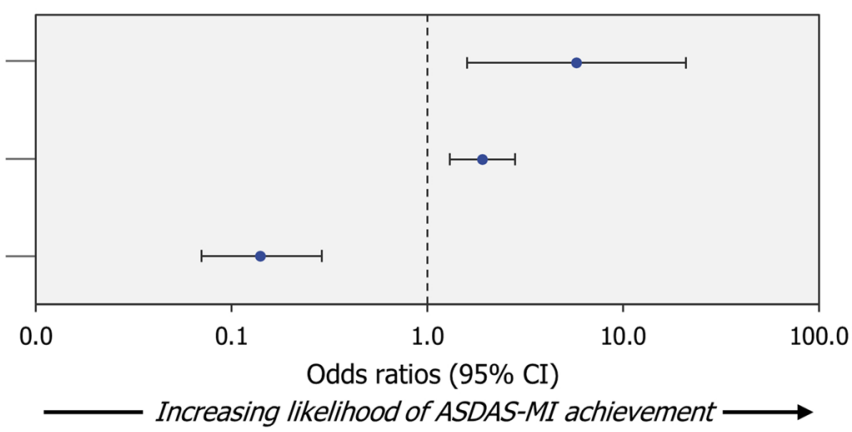

$5.78(1.59-20.98)$

$1.91(1.30-2.80)$

$0.14(0.07-0.29)$

\section{B) Predictive factors for ASAS40}

$\mathrm{MRI}+/ \mathrm{HLA}-\mathrm{B} 27+(\mathrm{n}=90)$ vs MRI-/HLA-B27+ $(n=38)$

Baseline BASM (greater vs smaller) $^{\mathrm{a}}$

Smaller improvement in PtGADA at Week 12 (vs greater improvement)

Smaller improvement in ASQoL at Week 12 (vs greater improvement) ${ }^{a}$

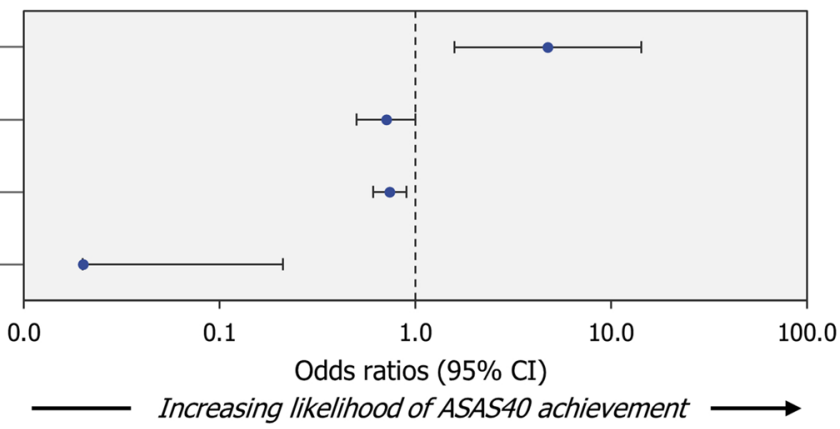

Odds ratio (95\% CI)

$4.75(1.58-14.28)$

$0.71(0.50-0.999)$

$0.74(0.61-0.90)$

$0.02(0.002-0.21)$

Odds ratio $(95 \% \mathrm{CI})$

\section{C) Predictive factors for BASDAI50}

MRI $+/ H L A-B 27+(n=90)$ vs MRI-/HLA-B27+ $(n=38)$ MASES (no vs yes)

Smaller improvement in BASDAI at Week 12 (vs greater improvement)a

Smaller improvement in ASQoL at Week 12 (vs greater improvement)

$$
0.0
$$

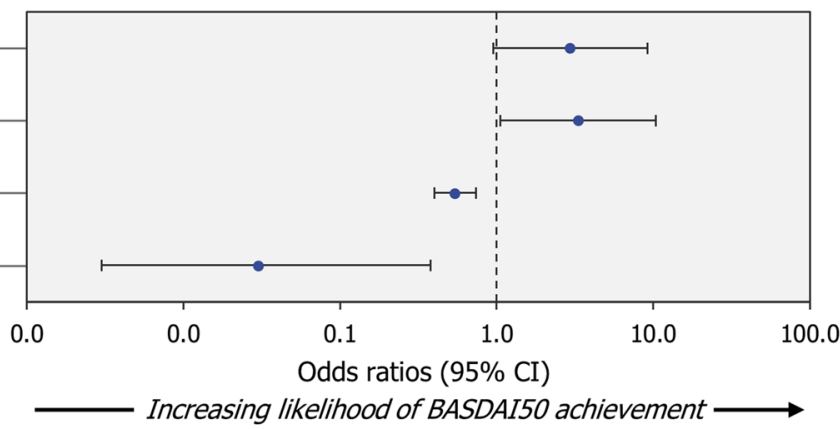

$2.94(0.95-9.16)$

$3.32(1.06-10.42)$

$0.54(0.40-0.74)$

$0.03(0.003-0.38)$

\section{D) Predictive factors for ASDAS-ID}

Odds ratio (95\% CI)

$$
\begin{array}{r}
\text { MRI } \\
\text { (positive vs negative) } \\
\text { Prior NSAIDs } \\
(\leq 2 \text { vs }>2) \\
\text { ASDAS-ID at Week } 12 \\
(\text { yes vs no) } \\
\text { Baseline BASFI } \\
\text { (greater vs smaller) }^{a}
\end{array}
$$

Smaller improvement in BASDAI at Week 12 (vs greater improvement)

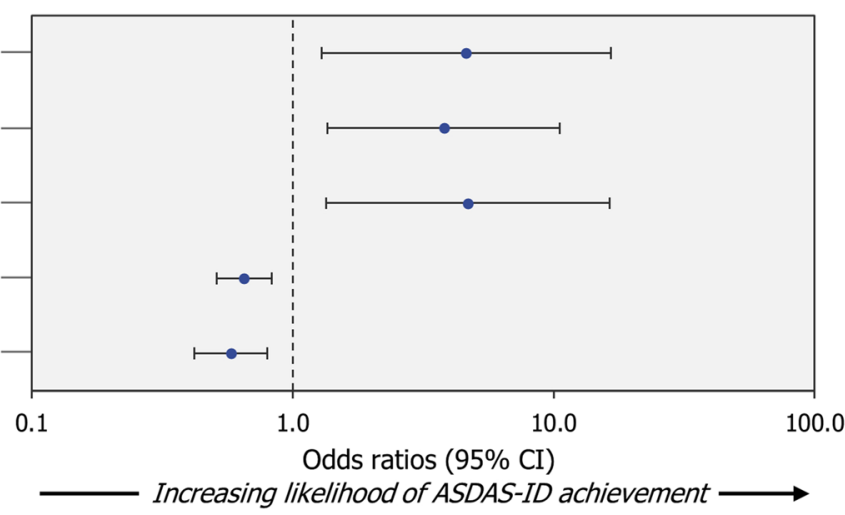

$4.62(1.29-16.61)$

$3.79(1.36-10.57)$

$4.69(1.34-16.42)$

$0.65(0.51-0.83)$

$0.58(0.42-0.80)$

Fig. 2 (See legend on previous page.) 
Table 3 Summary of Week 12 and Week 52 predictive factors of response in CZP-treated patients

\begin{tabular}{|c|c|c|}
\hline Response & Week 12 & Week 52 \\
\hline ASDAS-MI & $\begin{array}{l}\text { - Younger age } \\
\text { - Male sex } \\
\text { - Elevated CRP } \\
\text { - Higher PtGADA at baseline }\end{array}$ & $\begin{array}{l}\text { - MRI+/HLA-B27+ } \\
\text { - Higher BASDAI at baseline } \\
\text { - Greater Week } 12 \text { ASDAS improvement }\end{array}$ \\
\hline ASAS40 & $\begin{array}{l}\text { - Younger age } \\
\text { - Male sex }\end{array}$ & $\begin{array}{l}\text { - MRI+/HLA-B27+ } \\
\text { - Lower BASMI at baseline } \\
\text { - Greater Week } 12 \text { PtGADA and ASQoL improvements }\end{array}$ \\
\hline BASDAI50 & $\begin{array}{l}\text { - Younger age } \\
\text { - Male sex }\end{array}$ & $\begin{array}{l}\text { - MRI+/HLA-B27+ } \\
\text { - MASES =0 } \\
\text { - Greater Week } 12 \text { BASDAl and ASQoL improvements }\end{array}$ \\
\hline ASDAS-ID & $\begin{array}{l}\text { - Younger age } \\
\text { - Male sex }\end{array}$ & $\begin{array}{l}\text { - Positive MRI } \\
\text { - } \leq 2 \text { prior NSAIDs } \\
\text { - ASDAS-ID at Week } 12 \\
\text { - Lower BASFI at baseline } \\
\text { - Greater Week } 12 \text { BASDAl improvement }\end{array}$ \\
\hline
\end{tabular}

ASAS40 Assessment of SpondyloArthritis International Society 40\%, ASDAS Ankylosing Spondylitis Disease Activity Score, ASDAS-ID ASDAS inactive disease (ASDAS $<1.3$ ), ASDAS-MI ASDAS major improvement (reduction in ASDAS $\geq 2.0$ ), ASQoL Ankylosing Spondylitis Quality of Life, BASDAI50 Bath Ankylosing Spondylitis Disease Activity Index 50\%, BASMI Bath Ankylosing Spondylitis Metrology Index, HLA-B27 human leukocyte antigen-B27, MRI magnetic resonance imaging, MASES Maastricht Ankylosing Spondylitis Enthesitis Score (range 0-13), NSAID non-steroidal anti-inflammatory drug, PtGADA Patient Global Assessment of Disease Activity

Table 4 Interaction effects analysis for the Week 12 and Week 52 predictor models

\begin{tabular}{|c|c|c|c|c|c|c|c|c|}
\hline \multirow[b]{2}{*}{ Interaction effect } & \multicolumn{4}{|l|}{ Week 12} & \multicolumn{4}{|l|}{ Week 52} \\
\hline & ASDAS-MI & ASAS40 & BASDAI50 & ASDAS-ID & ASDAS-MI & ASAS40 & BASDAI50 & ASDAS-ID \\
\hline$M R I^{*} H L A-B 27$ & 0.5599 & 0.8460 & 0.1517 & 0.6183 & $0.0035^{*}$ & $0.0014^{*}$ & $0.0049 *$ & $0.0247^{*}$ \\
\hline Sex*MRI & 0.6680 & 0.3600 & 0.6663 & 0.9666 & $0.0005^{*}$ & 0.9107 & 0.1873 & $0.0030 *$ \\
\hline $\mathrm{Age}^{*} \mathrm{MRI}$ & 0.8676 & 0.5666 & 0.0916 & 0.2039 & 0.9140 & 0.8291 & 0.4061 & 0.7247 \\
\hline$C R P * M R I$ & 0.8584 & 0.4112 & 0.7003 & 0.0681 & 0.0626 & 0.7511 & 0.7955 & 0.4636 \\
\hline $\mathrm{Sex}^{*} \mathrm{CRP}$ & 0.7179 & 0.3568 & 0.5063 & 0.8552 & 0.8904 & 0.7033 & 0.6215 & 0.2282 \\
\hline Age $^{*} C R P$ & 0.9958 & 0.4325 & 0.0985 & 0.5441 & 0.0526 & 0.3986 & 0.9907 & 0.3007 \\
\hline
\end{tabular}

$p$-values from the final regression step are reported. *Significant interaction terms included in the final model. ASAS40 Assessment of SpondyloArthritis International Society 40\%, ASDAS Ankylosing Spondylitis Disease Activity Score, ASDAS-ID ASDAS inactive disease (ASDAS $<1.3$ ), ASDAS-MI ASDAS major improvement (reduction in ASDAS $\geq 2.0$ ), BASDAI50 Bath Ankylosing Spondylitis Disease Activity Index 50\%, HLA-B27 human leukocyte antigen-B27, MRI magnetic resonance imaging

\section{Abbreviations}

ASAS40: Assessment of SpondyloArthritis International Society 40\% response; ASQoL: Ankylosing spondylitis quality of life; ASDAS: Ankylosing Spondylitis Disease Activity Score; ASDAS-ID: ASDAS inactive disease; ASDAS-MI: ASDAS major improvement; axSpA: Axial spondyloarthritis; BASDAI50: Bath Ankylosing Spondyloarthritis Disease Activity Index 50\% response; BASFI: Bath Ankylosing Spondyloarthritis Functional Index; CRP: C-reactive protein; CZP: Certolizumab pegol; FDA: Food and Drug Administration; HLA-B27: Human leukocyte antigen-B27; MASES: Maastricht Ankylosing Spondylitis Enthesitis Score; MRI: Magnetic resonance imaging; mNY: Modified New York; NBBM: Non-biologic background medication; nr-axSpA: Non-radiographic axSpA; NSAID: Non-steroidal anti-inflammatory drug; OMERACT: Outcome Measures in Rheumatology; PtGADA: Patient Global Assessment of Disease Activity; r-axSpA: Radiographic axSpA; SIJ: Sacroiliac joint; TNFi: Tumour necrosis factor inhibitor; ULN: Upper limit of normal; USA: United States of America.

\section{Supplementary Information}

The online version contains supplementary material available at https://doi. org/10.1186/s13075-021-02650-4.

Additional file 1: Supplementary Appendix.

\section{Acknowledgements}

The authors thank the patients, the investigators and their teams who took part in this study. The authors also acknowledge Abbie Rogers, BSc, from Costello Medical, UK, for medical writing and editorial assistance based on the authors' input and direction. This study was funded by UCB Pharma.

\section{Authors' contributions}

Substantial contributions to the study conception and design: WPM, TK, SEA $B H, L B$ and $M R$; substantial contributions to the analysis and interpretation of the data: WPM, TK, SEA, BH, LB and MR; drafting the article or revising it critically for important intellectual content: WPM, TK, SEA, BH, LB and MR; final approval of the version of the article to be published: WPM, TK, SEA, BH, LB and MR.

\section{Funding}

This study was sponsored by UCB Pharma. This article was based on the C-axSpAnd study (NCT02552212) sponsored by UCB Pharma. Support for third-party writing assistance for this article, provided by Abbie Rogers, BSC, Costello Medical, UK, was funded by UCB Pharma in accordance with Good Publication Practice (GPP3) guidelines (http://www.ismpp.org/gpp3).

\section{Availability of data and materials}

Data from this manuscript may be requested by qualified researchers 6 months after product approval in the USA and/or Europe, or global development is discontinued, and 18 months after trial completion. Investigators may 
request access to anonymised IPD and redacted study documents which may include raw datasets, analysis-ready datasets, study protocol, blank case report form, annotated case report form, statistical analysis plan, dataset specifications and clinical study report. Prior to use of the data, proposals need to be approved by an independent review panel at www.Vivli.org, and a signed data sharing agreement will need to be executed. All documents are available in English only, for a pre-specified time, typically 12 months, on a passwordprotected portal.

\section{Declarations}

\section{Ethics approval and consent to participate}

C-axSpAnd was approved by institutional review boards and independent ethics committees at participating sites and was conducted in accordance with local regulations and the International Conference on Harmonization Good Clinical Practice requirements, based on the Declaration of Helsinki. All patients provided written informed consent to participate.

\section{Consent for publication}

Not applicable.

\section{Competing interests}

WPM: honoraria/consulting fees from AbbVie, Boehringer-Ingelheim, Celgene, Eli Lilly, Galapagos, Janssen, Novartis, Pfizer and UCB Pharma; research grants from AbbVie and Pfizer; educational grants from AbbVie, Janssen, Novartis and Pfizer; Chief Medical Officer for CARE Arthritis Limited. TK, SEA, BH and LB: employees of UCB Pharma; own stock awards in UCB Pharma. MR: speakers bureau for AbbVie, Eli Lilly, Novartis and UCB Pharma; consultant of AbbVie, Celgene, Eli Lilly, Janssen, Novartis and UCB Pharma.

\section{Author details}

${ }^{1}$ University of Alberta, Edmonton, Canada. ${ }^{2}$ UCB Pharma, Monheim am Rhein, Germany. ${ }^{3}$ UCB Pharma, Milan, Italy. ${ }^{4}$ University of Bielefeld, Klinikum Bielefeld, Bielefeld, Germany.

Received: 14 June 2021 Accepted: 12 October 2021

Published online: 29 October 2021

\section{References}

1. Rudwaleit M, van der Heijde D, Khan MA, Braun J, Sieper J. How to diagnose axial spondyloarthritis early. Ann. Rheum. Dis. 2004;63(5):535-43.

2. Rudwaleit M, Khan MA, Sieper J. The challenge of diagnosis and classification in early ankylosing spondylitis: do we need new criteria? Arthritis Rheum. 2005:52(4):1000-8.

3. Poddubnyy D. Classification vs diagnostic criteria: the challenge of diagnosing axial spondyloarthritis. Rheumatology (Oxford). 2020;59(Suppl 4):iv6-17.

4. Hunter T, Sandoval D, Booth N, Holdsworth E, Deodhar A. Comparing symptoms, treatment patterns, and quality of life of ankylosing spondylitis and non-radiographic axial spondyloarthritis patients in the USA: findings from a patient and rheumatologist Survey. Clin. Rheumatol. 2021:40(8):3161-7.

5. Kiwalkar S, Deodhar A, Howard R. "Rheum to diagnosis": uncovering impediments to accurate diagnosis of non-radiographic axial spondylarthritis (nr-axSpA). Arthritis Rheumatol. 2020;72(Suppl 10):1-4231.

6. Protopopov M, Poddubnyy D. Radiographic progression in nonradiographic axial spondyloarthritis. Expert Rev Clin Immunol. 2018;14(6):525-33.

7. Mandl P, Navarro-Compán V, Terslev L, Aegerter P, van der Heijde D, Agostino MA, et al. EULAR recommendations for the use of imaging in the diagnosis and management of spondyloarthritis in clinical practice. Ann. Rheum. Dis. 2015;74(7):1327.

8. van der Heijde D, Ramiro S, Landewé R, Baraliakos X, Van den Bosch F, Sepriano A, et al. 2016 update of the ASAS-EULAR management recommendations for axial spondyloarthritis. Ann. Rheum. Dis. 2017;76(6):978-91.
9. Sieper J, van der Heijde D, Dougados M, Mease PJ, Maksymowych WP, Brown MA, et al. Efficacy and safety of adalimumab in patients with nonradiographic axial spondyloarthritis: results of a randomised placebocontrolled trial (ABILITY-1). Ann. Rheum. Dis. 2013;72(6):815-22.

10. Sieper J, van der Heijde D, Dougados M, Maksymowych WP, Scott $\mathrm{BB}$, Boice JA, et al. A randomized, double-blind, placebo-controlled, sixteen-week study of subcutaneous golimumab in patients with active nonradiographic axial spondyloarthritis. Arthritis Rheumatol. 2015;67(10):2702-12.

11. Dougados M, van der Heijde D, Sieper J, Braun J, Maksymowych WP, Citera $\mathrm{G}$, et al. Symptomatic efficacy of etanercept and its effects on objective signs of inflammation in early nonradiographic axial spondyloarthritis: a multicenter, randomized, double-blind, placebo-controlled trial. Arthritis Rheumatol. 2014;66(8):2091-102.

12. Rudwaleit M, Schwarzlose S, Hilgert ES, Listing J, Braun J, Sieper J. MRI in predicting a major clinical response to anti-tumour necrosis factor treatment in ankylosing spondylitis. Ann. Rheum. Dis. 2008;67(9):1276-81.

13. Rudwaleit M, Listing J, Brandt J, Braun J, Sieper J. Prediction of a major clinical response (BASDAI 50) to tumour necrosis factor alpha blockers in ankylosing spondylitis. Ann. Rheum. Dis. 2004;63(6):665-70.

14. Davis JC Jr, Van der Heijde DM, Dougados M, Braun J, Cush JJ, Clegg $\mathrm{DO}$, et al. Baseline factors that influence ASAS 20 response in patients with ankylosing spondylitis treated with etanercept. J. Rheumatol. 2005;32(9):1751-4.

15. Rudwaleit M, Claudepierre P, Wordsworth P, Cortina EL, Sieper J, Kron M, et al. Effectiveness, safety, and predictors of good clinical response in 1250 patients treated with adalimumab for active ankylosing spondylitis. J. Rheumatol. 2009;36(4):801-8.

16. Glintborg B, Ostergaard M, Krogh NS, Dreyer L, Kristensen HL, Hetland ML. Predictors of treatment response and drug continuation in 842 patients with ankylosing spondylitis treated with anti-tumour necrosis factor: results from 8 years' surveillance in the Danish nationwide DANBIO registry. Ann. Rheum. Dis. 2010;69(11):2002-8.

17. Arends S, Brouwer E, van der Veer E, Groen H, Leijsma MK, Houtman $\mathrm{PM}$, et al. Baseline predictors of response and discontinuation of tumor necrosis factor-alpha blocking therapy in ankylosing spondylitis: a prospective longitudinal observational cohort study. Arthritis Res. Ther. 2011;13(3):R94

18. Maneiro JR, Souto A, Salgado E, Mera A, Gomez-Reino JJ. Predictors of response to TNF antagonists in patients with ankylosing spondylitis and psoriatic arthritis: systematic review and meta-analysis. RMD open. 2015;1(1):e000017.

19. Vastesaeger N, van der Heijde D, Inman RD, Wang Y, Deodhar A, Hsu B, et al. Predicting the outcome of ankylosing spondylitis therapy. Ann. Rheum. Dis. 2011;70(6):973-81.

20. FDA. Certolizumab pegol Product Information (2019). https://www.acces sdata.fda.gov/drugsatfda_docs/label/2019/125160s237lbl.Pdf Accessed 25 January 2021.

21. Deodhar A, Gensler LS, Kay J, Maksymowych WP, Haroon N, Landewé $\mathrm{R}$, et al. A fifty-two-week, randomized, placebo-controlled trial of certolizumab pegol in nonradiographic axial spondyloarthritis. Arthritis Rheumatol. 2019;71(7):1101-11.

22. Machado P, Landewé R, Lie E, Kvien TK, Braun J, Baker D, et al. Ankylosing Spondylitis Disease Activity Score (ASDAS): defining cut-off values for disease activity states and improvement scores. Ann. Rheum. Dis. 2011;70(1):47.

23. Rudwaleit M, van der Heijde D, Landewé R, Listing J, Akkoc N, Brandt J, et al. The development of Assessment of SpondyloArthritis international Society classification criteria for axial spondyloarthritis (part II): validation and final selection. Ann. Rheum. Dis. 2009;68(6):777-83.

24. Rudwaleit M, Jurik AG, Hermann KG, Landewé R, van der Heijde D, Baraliakos $X$, et al. Defining active sacroiliitis on magnetic resonance imaging (MRI) for classification of axial spondyloarthritis: a consensual approach by the ASAS/OMERACT MRI group. Ann. Rheum. Dis. 2009;68(10):1520-7.

25. van der Linden S, Valkenburg HA, Cats A. Evaluation of diagnostic criteria for ankylosing spondylitis. A proposal for modification of the New York criteria. Arthritis Rheum. 1984;27(4):361-8.

26. Sieper J, Landewé R, Magrey M, Anderson JK, Zhong S, Wang X, et al. Predictors of remission in patients with non-radiographic axial 
spondyloarthritis receiving open-label adalimumab in the ABILITY-3 study. RMD open. 2019;5(1):e000917.

27. Rusman T, van Vollenhoven RF, van der Horst-Bruinsma IE. Gender differences in axial spondyloarthritis: women are not so lucky. Curr Rheumatol Rep. 2018;20(6):35.

28. Neuenschwander R, Hebeisen M, Micheroli R, Bürki K, Exer P, Niedermann $K$, et al. Differences between men and women with nonradiographic axial spondyloarthritis: clinical characteristics and treatment effectiveness in a real-life prospective cohort. Arthritis Res. Ther. 2020;22(1):233.

29. Maksymowych WP, Dougados M, van der Heijde D, Sieper J, Braun J, Citera G, et al. Clinical and MRI responses to etanercept in early nonradiographic axial spondyloarthritis: 48-week results from the EMBARK study. Ann. Rheum. Dis. 2016;75(7):1328.

30. Glintborg B, Sørensen IJ, Østergaard M, Dreyer L, Mohamoud AA, Krogh NS, et al. Ankylosing spondylitis versus nonradiographic axial spondyloarthritis: comparison of tumor necrosis factor inhibitor effectiveness and effect of HLA-B27 status. An observational cohort study from the Nationwide DANBIO Registry. J. Rheumatol. 2017:44(1):59-69.

31. Moltó A, Paternotte S, Claudepierre P, Breban M, Dougados M. Effectiveness of tumor necrosis factor a blockers in early axial spondyloarthritis: data from the DESIR cohort. Arthritis Rheumatol. 2014;66(7):1734-44.

\section{Publisher's Note}

Springer Nature remains neutral with regard to jurisdictional claims in published maps and institutional affiliations.

- fast, convenient online submission

- thorough peer review by experienced researchers in your field

- rapid publication on acceptance

- support for research data, including large and complex data types

- gold Open Access which fosters wider collaboration and increased citations

- maximum visibility for your research: over $100 \mathrm{M}$ website views per year

At BMC, research is always in progress.

Learn more biomedcentral.com/submissions 